\title{
ON BECOMING AN AUTONOMOUS TEACHING PROFESSIONAL: MAPPING STAFF PROFESSIONAL DEVELOPMENT PREFERENCES
}

\author{
Amy Benians and Daniel Fridberg
}

\section{INTRODUCTION}

The Learning and Teaching Development (LTD) team at Otago Polytechnic (OP) is a service centre that provides support and professional development (PD) for staff in Learning and Teaching. LTD is tasked with planning and designing workshops, modules and bespoke training to support the teaching staff at OP. This positions LTD at the junction of adult education, teacher training and organisational learning.

To articulate this point, let's consider these three components in turn. Adult education lends itself to self-directed learning, where an individual identifies their learning needs, decides on goals, discovers resources and strategies for learning and then self-evaluates (Knowles, 1980); teacher training lends itself to experiential forms of learning (Timperley \& Alton-Lee, 2008); and organisational learning lends itself to situated cognition, which recognises that knowledge is embedded within the context in which the activity occurs, and in the organisational language and culture to which it pertains (Brown et al., 1989). In these different areas, LTD supports individuals in providing adult education, training teachers in pedagogy and course development, and works with programme teams across the organisation to embed strategic frameworks and establish learning groups and communities of practice (CoPs).

While professional learning within these three areas can, at times, seem to present competing demands, examining the literature on learning in each of these broad areas (see, for example, Knowles, 1980; Hansman, 2008) reveals that these pedagogies are complementary rather than competing. All revolve around shared educational values that closely align to our OP values of courage, caring, empowerment and accountability.

For example, in the Adult Learning space, as an individual teacher develops in their teaching role, they start to identify their own learning needs to best support their students and become increasingly self-directed and autonomous in pursuit of these learning goals (Hansman, 2008). In the space of Teacher Training, there is an expectation at $O P$ that teaching staff hold a formal qualification in tertiary education. Often tertiary educators have specialised expertise in their trade or discipline, but they may not have a teaching qualification or a background in Learning and Teaching (Viskovic, 2005). At OP this initial teacher training is provided by LTD through the Graduate Diploma in Tertiary Education (GDTE). Thereafter, teachers at OP are encouraged to engage in continuing PD in their discipline as well as in Learning and Teaching, with ongoing support from LTD. Finally, in the Organisational Learning space, situated learning describes how individuals acquire embedded knowledge, learn to use the "tools of their trade," and refine these skills within the context that the knowledge, tools and skills will be used in their practice. Furthermore, sharing in embedded knowledge can happen through situated learning in real-world organisational contexts, either as individuals (Brown et al., n.d.) or within CoPs (Lave \& Wenger, 1991). 
So, what are CoPs? These are broadly defined as groups of people who share a concern or passion for something that they do and learn how to do it better as they interact regularly (Wenger \& Snyder, 2000). The key driver for people to assemble in CoPs is the situated learning that takes place (Lave \& Wenger, 1991). The CoP framework has been widely used in education to create learning communities which are established by teachers, for students, to engage students in a community of practice (CoP) pedagogy. As an example of a learning community, students may be tasked with a joint enterprise such as arranging an art exhibition with alumni (Wassenaar, 2017). They accomplish this by collectively engaging as a community, and in so doing develop a shared repertoire, including artifacts, resources and documentation, and arrive at a common language that they develop as a group. Such learning communities have been found to be very useful in reducing the isolation of online or distance learners (Andrew, 2014).

The CoP framework is a frequently used model of PD at OP. These are working groups of staff interested in broadening their understanding and increasing their competency in specific areas of Learning and Teaching, including educational technology, academic supervision and mentorship, and teaching peer-observation.

As a Learning and Teaching unit, one of the reasons for our interest in models of PD was a number of papers by Aileen Kennedy $(2005,2014)$ of the University of Strathclyde. In these papers, she examined different models for continuing professional development for teachers. She categorised these on a spectrum from transmissive to transitional to transformative. In her classification, she considered teachers' professional autonomy in undertaking PD, accountability for PD and the power relations underlying the reasons for taking up PD (Figure I). In Kennedy's schematic, "transformative" refers to models of PD in which a teacher has professional and intellectual autonomy; she argues that such transformative PD models have the capacity to bring about lasting educational change.

\begin{tabular}{|l|l|l|}
\hline Model of PD & Purpose of model \\
\hline $\begin{array}{l}\text { The training model } \\
\text { The award-bearing model } \\
\text { The deficit model } \\
\text { The cascade model }\end{array}$ & Transmissive & \\
\hline $\begin{array}{l}\text { The standards-based model } \\
\text { The coaching/mentoring model } \\
\text { The community of practice model }\end{array}$ & Transitional & $\begin{array}{l}\text { Increasing capacity for professional } \\
\text { autonomy and teacher agency }\end{array}$ \\
\hline $\begin{array}{l}\text { The action research model } \\
\text { The transformative model }\end{array}$ & Transformative & \\
\hline
\end{tabular}

Figure I. Kennedy's spectrum of PD models (Kennedy, 2005, 2014).

We wished to examine how Kennedy's model translates in our own practice of delivering PD. Based on relevant literature (see, for example, Hudson, 2016; Manke, 1997; Wong, 2016), we have articulated two factors that might promote teachers' increased autonomy in pursuing PD:

I. Reduction of the hierarchical nature of the interaction between PD provider and recipient.

2. Having the direction of information flow change from unidirectional to bidirectional, as we move from the transmissive to the transformative. 
Thus, theoretically, as we move from transmissive towards transformative PD, the learner becomes more autonomous, self-driven and self-directed in their learning. To illustrate this with an example, the CoP model of PD sits in the transitional zone in Figure I. Within a CoP, information flow is bidirectional and usually occurs within a democratic structure, reducing the hierarchy between expert and novice learner. However, there is still an expectation within a CoP for facilitation and leadership which sets the mandate for the group (Wenger \& Snyder, 2000). Of interest to us, as staff developers, is that as one moves from a transmissive towards a transformative model of PD, there is an increasing capacity for professional autonomy, whereby the staff member engaging in $\mathrm{PD}$ has a greater capacity to decide on the direction that they wish to engage in self-directed learning. Figure 2 illustrates how these factors relate to Kennedy's modes of PD.

\begin{tabular}{|c|c|c|c|}
\hline & & \multicolumn{2}{|c|}{ Criterion I: Teacher-learner hierarchy present } \\
\hline & & Yes & No \\
\hline \multirow{2}{*}{$\begin{array}{l}\text { Criterion 2: Direction of } \\
\text { information flow }\end{array}$} & One way & Transmissive & \\
\hline & Two ways & Transitional & Transformative \\
\hline
\end{tabular}

Figure 2. PD classification criteria.

Some examples that illustrate these criteria include a face-to-face workshop, in which a one-way information flow takes places with a hierarchical division between an expert facilitator and learners. Conversely, in a peer-mentoring circle, no formal roles are allocated and information flows in all directions, making it a transformative means of PD.

To summarise, LTD is involved in designing and delivering PD in different settings (individual, group-based and institutional), ranging from transmissive methods of delivery to more autonomous, transformative ones. One predominant form of PD, which promotes learners' autonomy, though not yet manifesting full autonomy, is the CoP model, which is a widely practiced form of PD at OP. Based on this practice, in our research we sought to answer the question: What are OP's staff preferences for their own PD in terms of Kennedy's spectrum? Following on from this initial question, we explored the existing CoPs in which OP staff play an active role and classified them.

\section{METHODS}

Data was collected for quantitative and qualitative analysis using an anonymous survey in Qualtrics that was emailed to all teaching staff at OP across three campuses (Dunedin, Cromwell and Auckland). Staff were invited to participate in this survey in July 2020, allowing 5-6 weeks return to normal campus-based teaching following the COVID-19 related lockdown. Ethics approval for this research was obtained from OP's research ethics committee (reference number 864a).

The survey consisted of three parts. In the first part, multiple-choice demographic questions were asked about gender, ethnicity, campus, years of teaching and other personal data. In the second part, teachers were asked about their preferred ways of receiving PD (for example, face-to-face workshops and online workshops) and about areas of Learning and Teaching in which they would like to be better able to support their learners. In the third part, teachers were asked questions relating to CoP, enquiring if the staff member was a member of any CoPs and, if so, the names and purposes of these (with a maximum of three). 


\section{Community of Practice Mapping}

To map OP's staff CoPs, a thematic analysis of the names and purposes of the CoPs described at OP was performed, based on the procedure described by Boyatzis (1998). Themes were not pre-decided, but were allowed to emerge from the data through an initial inspection of a subset of the data by the first author. Themes were coded as follows:

I. Learning and Teaching - to include all activities related to teacher training, apprenticeships and classroom teaching.

2. Educational technologies.

3. Professional identity - to include all professional registration bodies, such as Chambers of Commerce, and groups contributing to staff development within their discipline area.

4. Research.

5. Cultural or related to ethnicity.

6. Wellbeing or related to pastoral support of either students or staff members.

7. Not a CoP. This theme was to describe reported communities that were deemed to be lacking the element of practice (Wenger, 1998), such as a faith-based group.

The thematic analysis was conducted by three members of the research team to independently code the data set. An interrater reliability of 80 percent was reached, calculated as a percentage of the number of times the three researchers agreed on the codes, divided by the total. Disagreements were easily resolved through discussion of the coding and a consensus decision reached, after which the majority decision was taken as consensus.

\section{Kennedy Score}

In order to analyse our data in light of Kennedy's model (Kennedy, 2005), participants were classified by their preferred means of PD into three categories: transmissive, transitional and transformative. Next, a Kennedy Score (KS) ranging from I to 3 was calculated for each participant. Each classified mode (transmissive, transitional and transformative) received a value of I, 2 or 3 respectively. Then, numeric values were calculated as an average of a participant's choices between their five highest preferred PD modes. A high KS approaching 3 indicated a preference for transformational delivery of PD, while a low score approaching I indicated a preference for transmissive delivery of PD.

The SPSS data analysis package was used to perform quantitative analyses on the de-identified data set, including descriptive statistics and statistical tests to examine for relationships between variables such as bivariate analyses.

\section{RESULTS}

\section{Demographics}

The responses to the demographic questions indicated that of the 98 respondents, 37 were male and 55 were female. Of those, six identified as Māori and 92 were non-Māori and non-Pasifika. Roughly 70 percent of the respondents worked at the Dunedin campus at the time of taking the survey, which is reflective of OP's distribution across its three campuses, with a small number of respondents ( $\sim 4$ percent) at the Central Otago campus and a small but significant number of respondents ( $\sim 12$ percent) at the Auckland International campus. The around II percent who selected "other" were most likely staff working at distance around the country.

Of the respondents, more than half (56-57 percent) said that they had been working at OP for more than six years. The respondents' level of professional qualification is presented in Figure 3. 
What is your highest level professional qualification?



Figure 3. Respondents' level of professional qualification.

As Figure 3 shows, more than half of the respondents hold a Master's degree or above.

\section{Community of Practice mapping}

Forty-eight of the 98 participants felt that they belonged to one or more CoP. The CoPs mentioned by the participants are presented by themes in Figure 4.

\section{Type of Community of Practice}

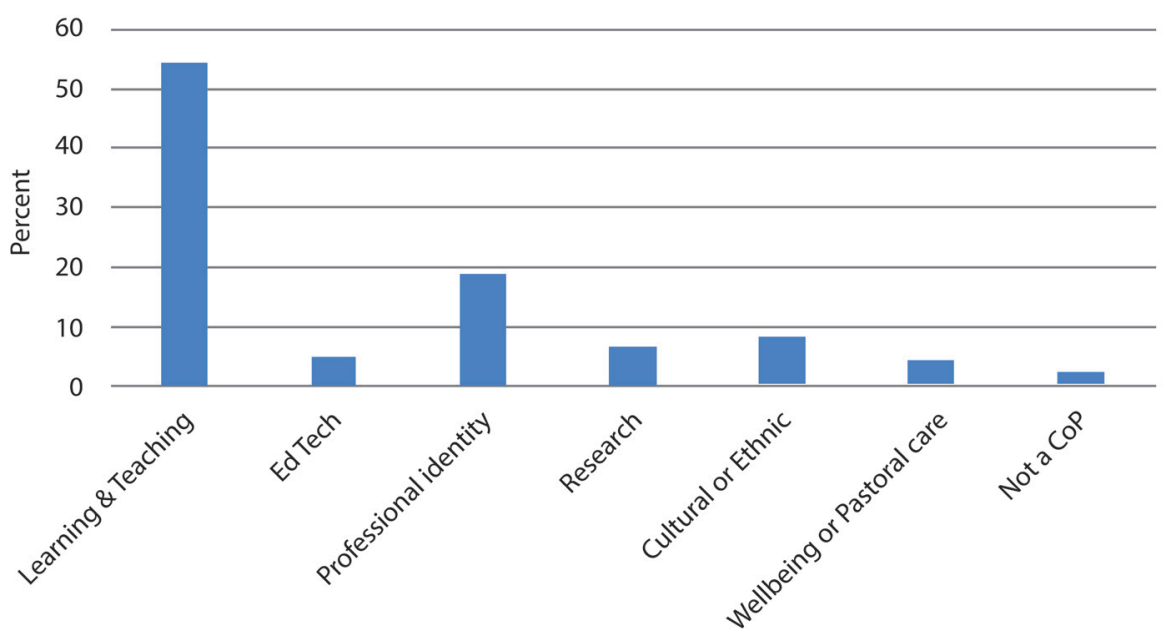

Figure 4. Type of CoP reported by participants. 
As Figure 4 indicates, 60 percent of the CoPs mentioned by the participants revolve around Learning and Teaching practice, including educational technology.

The 48 participants who are members of one CoP or more were then asked to what extent their participation in CoPs contributes to their practice. Their responses are summarised in Figure 5.

\section{To what extent does your participation in this group contribute to your practice?}

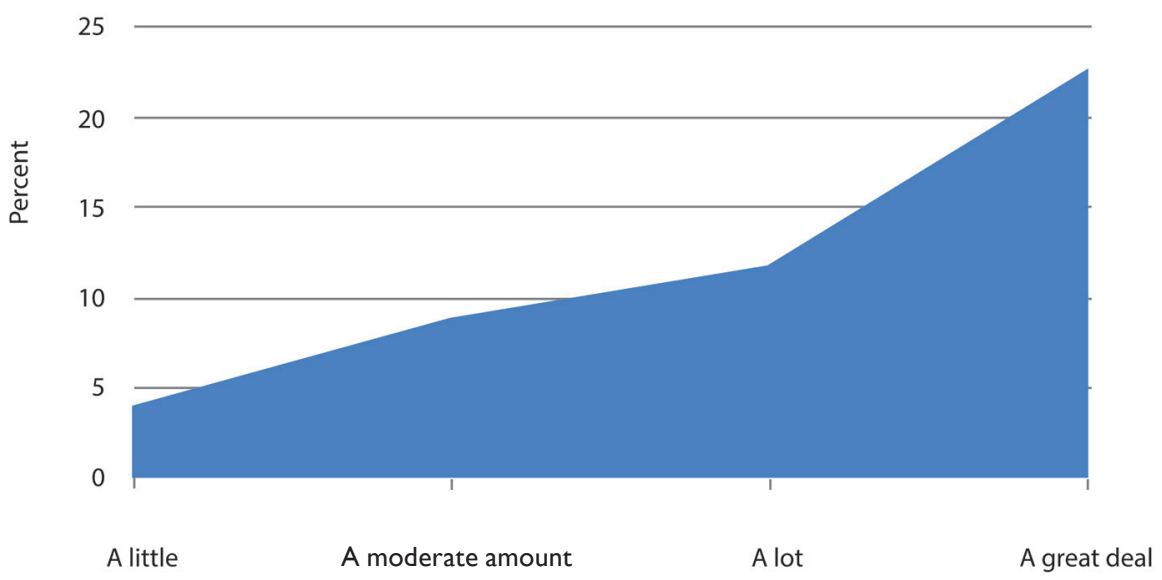

Figure 5. Participants' perceptions regarding contribution of CoPs to their practice.

Results were then examined for correlations. The length of time teaching was the only significant factor in determining membership of a CoP and perception of its value. Specifically, length of time teaching at OP was found to be positively correlated with belonging to one or more $\operatorname{CoP}(n=82, R=.287$. $P<.01)$. This means that the longer a teacher teaches at OP, the more likely they are to belong to a CoP. Also, the length of time teaching was found to be positively correlated with respondents' perceived contribution to their teaching practice of participation in a $\operatorname{CoP}(n=48, R=.290, P<.5)$. That is, the longer a teacher teaches, the more likely they are to see the value in participating in a CoP for their teaching practice. Other demographic variables, including gender, location, part- or full-time status and level of professional qualification, were not found to be less significant in this respect.

\section{Kennedy Score}

As a next step, respondents' KS were analysed, both to map their PD preference and to check for possible factors influencing it. The relative weightings of Kennedy's modes of PD in the participants' responses are presented in Figure 6. 


\section{How do you normally prefer to engage in PD?}

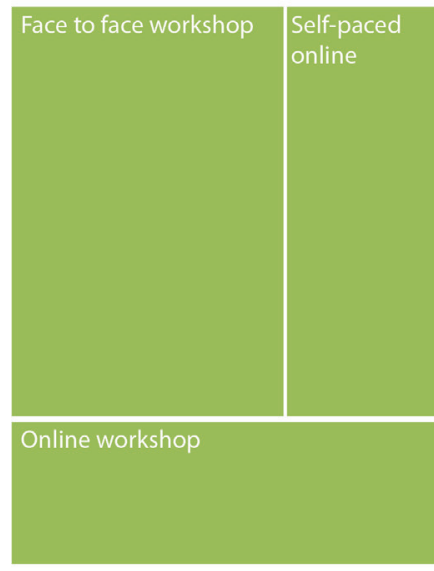

Transmissive

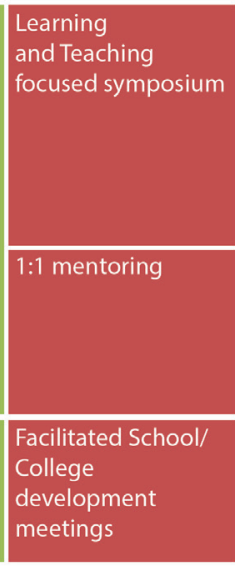

- Transitional

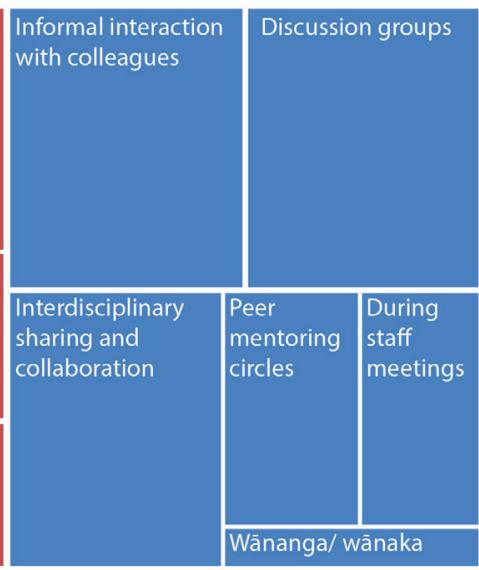

Transformative

Figure 6. Participants' preferences for modes of PD.

As Figure 6 shows, a majority of the participants, almost in equal numbers, have preferences for either transmissive or transformative modes of PD. Although it may seem as if there is a polarisation in participants' preferences of PD modes, further analysis indicates that there is a close-to-normal distribution of individuals' KS, with the mean KS being very close to 2 ( $N=91$, Mean=1.92, StD=.374). Figure 7 below presents the distribution of the participants' KS.

\section{Kennedy's score}

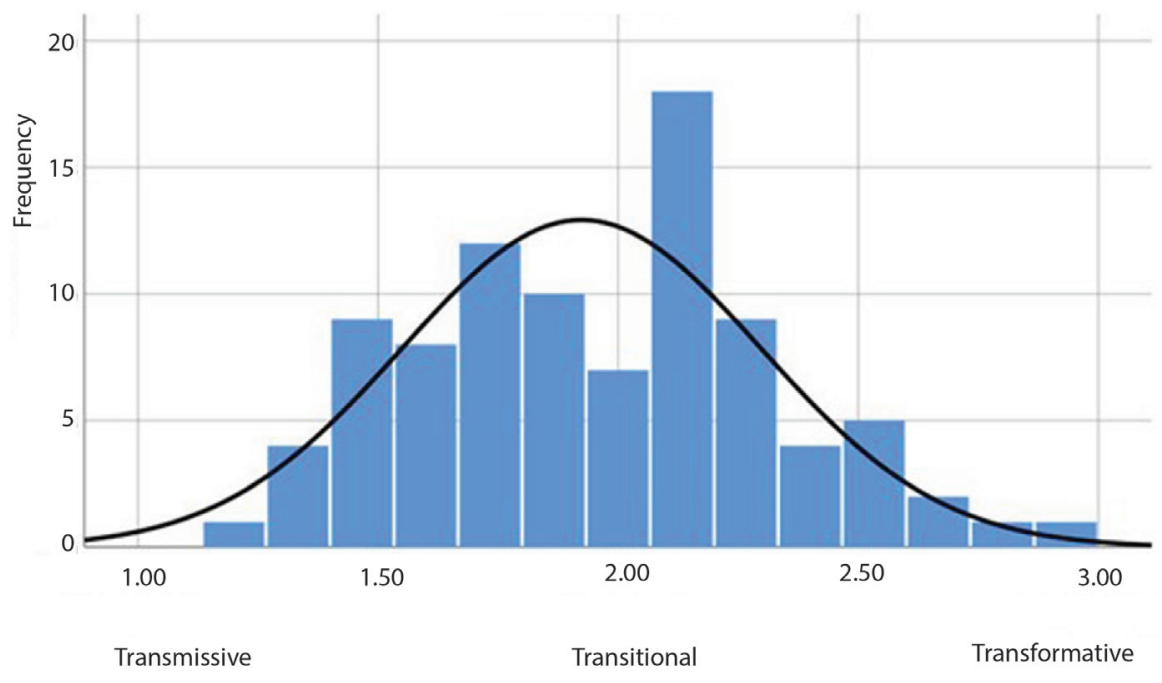

Figure 7. Participants' KS distribution. 
Following the distribution analysis, a correlation analysis was performed to identify possible factors which might influence participants' preference for one mode of PD over another. The findings indicated that time spent teaching is positively correlated with the $\mathrm{KS}(n=91, r=.257, p<.05)$, meaning that the longer a teacher teaches, the more they are inclined towards a transformative mode of PD. Furthermore, a T-test indicated that a likely cut-off point of length of teaching was six years $(n=91, t=.255 . p<.05)$. Conversely, this finding indicates that teachers with less than six years of teaching experience have a preference for PD modes positioned on the transitional-transmissive area of the KS spectrum. No other demographic factors were found to have a significant effect on participants' KS.

\section{DISCUSSION}

Our research aimed to address two main questions - what are OP's staff preferences for their own PD, in terms of Kennedy's spectrum; and what are the existing CoPs in which OP staff play an active role? This section presents the main findings on these questions, exploring some of their theoretical meanings. Next, implications for OP staff development are explored, for the LTD team as well at the institutional level. Finally, the next steps for this research project are presented.

With regard to the first research question, Kennedy (2005) argues that the progress along the spectrum of PD modes supports the development of professional autonomy and capacity for transformative practice. Our results indicate that while this may be very much the case, a time factor should also be integrated into this model, to allow new teachers to gain competency by engaging in transmissive modes of PD before they have the confidence and capability to engage in more autonomous forms of PD.

The KS, while being important in introducing a conceptual framework for teachers' PD, does not fully address the question of causality. That is, why are different modes preferred by different teachers and, more importantly, what factors drive progression along the spectrum? The results of our research suggest that not only do PD needs change with time spent teaching, but that teachers' expressed PD preferences might provide an indication of their perception of agency. In other words, beyond the specific value that a PD opportunity holds for professional learning, a progression in the PD mode goes hand-in-hand with an increased sense of competence and development of professional identity.

Additionally, while Kennedy infers that the shift towards transformative PD reflects an increase in professional and intellectual autonomy (2005) and teacher agency (2014), she does not relate this to a teacher's preference for more autonomous forms of PD that we think this shift entails. To bridge this gap, we have postulated that this shift towards greater professional/intellectual autonomy also involves a preference for engaging in self-directed learning pedagogies. More specifically, where developing an autonomous learner is a goal of the PD, we have elaborated on two factors, namely removing teacher-learner hierarchies and encouraging two-way information flow. These two factors may provide guidelines for practical applications for PD which can allow staff to move towards more autonomous modes of PD.

In regard to the second question, the research results indicate that OP's staff has diverse preferences when it comes to their preferred PD modes. While newer staff members prefer more transmissive modes of PD, it seems that the more experienced teachers prefer more autonomous modes, which are typically transitional or transformative. Not surprisingly, the more experienced teachers are, the more they are engaged in CoPs and the more likely they are to find them valuable in contributing to their teaching practice. The most common CoPs at OP revolve around Learning and Teaching issues (60 percent), with a few others that were classified as focussed on research (8 percent), professional or cultural identity (28 percent), and pastoral care and wellbeing (4 percent). These results provide a strong indication of the usefulness of CoPs as a means of Learning and Teaching-related PD. For this reason, the second phase of this research project will be dedicated to a closer examination of CoPs at OP. 


\section{Implications for Learning and Teaching Development}

In Kennedy's original classification, she used the terms transmissive, transitional and transformative to define the intended purpose of the PD undertaken. For example, transformative forms of PD such as action research could be used to bring about a transformative change in teaching practices utilising a ground-up approach, whereas transmissive forms of PD could be used for actioning an organisation-wide directive, such as encouraging staff to adopt a new literacy strategy or classroom teaching practice across an institution. The purpose of the transitional category includes forms of PD that can straddle both transmissive and transformative modes and can transition from one to the other. For example, the CoP model of PD can be facilitated in a strongly directive fashion, or it can be staff-led and evolve with their changing learning needs and interests. In this paper, we have used the terms transmissive, transitional and transformative to define the mode of delivery of PD. In so doing, we have broadened Kennedy's classification to also include the delivery mode as well as the intended purpose of the PD. Nevertheless, delivery mode strongly aligns to purpose. From LTD's perspective, this has implications for the design of PD, where the choice of delivery mode should align with the pedagogy used to deliver PD offerings and its intended purpose.

From our data, we also see an emerging group which consists of our new teachers who have just come into teaching practice from their trades or professions; they show a preference for more transmissive modes of PD. For their academic induction, our new teachers have a need for just-in-time learning such as targeted face-to-face workshops. Furthermore, examining the learners' pathway through the GDTE from the perspective of increasing learners' autonomy may illuminate a progression towards self-directed learning. Specifically, learners start this programme by working through fully facilitated courses (for example, Fundamentals of Tertiary Teaching and Learning), then moving onto supervised courses (for example, Negotiated Learning and Work-Based Learning) and through to self-directed learning (Integration of Professional Practice). Thus, the GDTE journey, which new teachers at $O P$ are required to take in their first few years of teaching, embodies this progression from transmissive to transitional to transformative modes of learning. Through the delivery of this programme, LTD hopes to promote an organisational culture of self-directed and autonomous learning.

Reflecting on the training and support offered by LTD to OP's staff, it is evident that much is offered in the space of transmissive PD in the form of the GDTE, online tutorials, face-to-face workshops and bespoke training; less is offered as transitional forms of PD, such as CoPs (for example, Educational Technology Champs or GDTE learners' hui); and very little if anything is offered as transformative PD. Considering the findings of our research, a major implication is that while support from LTD is mostly offered to newer staff members, the needs of more experienced staff should be given greater consideration and more emphasis by LTD.

\section{Institutional implications}

From an organisational perspective, an awareness of Kennedy's categorisation of PD models can inform decisions around staff development and support.

\section{Support of $O P$ teaching staff}

The constraints on available resources need to be considered. For transmissive modes of PD staff need time, such as the discretionary leave available to academic staff engaged in the GDTE and time-release from normal teaching duties. However, transitional and transformative modes are more resource-intensive, requiring funding for launch events, visiting speakers, conferences, and so on. However, these activities are highly unlikely to be eligible for research funding. One recommendation would be to make a pool of funding available for transitional and transformative PD opportunities such as these. 


\section{Reward and recognition of staff}

OP has some paths in place to recognise and incentivise transmissive PD: early-career teachers are awarded badges, OP's micro-credentials or "EduBits" and the GDTE qualification; mid-career teachers are awarded post-GDTE PD funding increases and eligibility to apply for senior lecturer status. However, we may lack forms of recognition for our mature-career teachers engaging in transitional and transformative modes of PD. There needs to be greater recognition for being part of institutional groups such as CoPs and research groups, which contribute to both one's own professional learning and that of colleagues.

\section{Next steps}

Viskovic's work indicates that vocational teachers value the informal learnings that are gained from within a CoP framework (Viskovic, 2005). A second reason to explore CoPs at OP is that CoPs represent a model of PD that empowers teaching staff to become self-directed in their learning (Hansman, 2008). Self-directed learning is the "holy grail" for staff developers who ideally want motivated, agentic and empowered staff members to identify areas for their own PD of interest to them as dual professionals, such as engaging in professional inquiry or research (Timperley et al., 2007).

In this first phase of the research project, questions on OP staff's PD preferences and needs were explored, CoPs were mapped and the perceived contribution of CoP to staff's PD was confirmed. However, there is still a need for an in-depth inquiry into why individuals participate in CoPs and the benefits for their teaching. Additionally, while a broad understanding of the areas covered by CoPs has been established, further research is required to learn about best practice in initiating and operating CoPs at OP. These two questions will be the focus of the second phase of our research project, using more qualitative tools and methodology. As a result, we hope to develop our understanding of how we can improve our support of CoPs as an organisation.

\section{ACKNOWLEDGEMENTS}

This article reports the first phase results of a research project focusing on CoPs at Otago Polytechnic. The authors would like to thank Rhina Chan, Kath Danaher and Rachel Cash for their generous contributions to data collection and analysis.

Amy Benians joined the Otago Polytechnic Learning and Teaching Development team in August 2018. She supports staff to design, develop and deliver blended and online courses using Moodle and other educational technologies. Prior to this, she worked as a research scientist, lecturer, scientific writer and instructional designer. She holds a PhD in clinical pharmacology from the University of London and a Graduate Diploma in Tertiary Education from Otago Polytechnic. Her research interests include teacher professional learning and development within CoPs, blended learning and student-centred learning and teaching.

(1) https://orcid.org/0000-0001-7600-6837

Daniel Fridberg joined the Otago Polytechnic Learning and Teaching Development team in September 2018. Prior to this, he was a practitioner, teacher and consultant in negotiation and peacebuilding processes. In his role as a learning and teaching specialist, he supports staff in developing their teaching practice. In 2022 he plans to launch a new Graduate Diploma in Conflict Resolution at Otago Polytechnic. Daniel holds a PhD in peace and conflict studies from the University of Otago. He has an MA in conflict research, management and resolution and a BA in psychology, both from the Hebrew University of Jerusalem.

(DD https://orcid.org/0000-0001-877/-9170 


\section{REFERENCES}

Andrew, M. (2014). Community and individuality: Teaching and learning insights from a postgraduate online writing program. Sage Open, 4(3), Article 2158244014544292. https://doi.org/I0.1 I77\%2F2I58244014544292

Bitterman, J. (2008). Utilizing CoPs: Concepts in adult education doctoral study. In C. Kimble, P. M. Hildreth, \& I. Bourdon (Eds.), CoPs: Creating Learning Environments for Educators (pp. 31I-332). Information Age Publishing.

Boyatzis, R. E. (1998). Transforming qualitative information: Thematic analysis and code development. Sage.

Brown, J. S., Collins, A., \& Duguid, P. (1989). Situated cognition and the culture of learning. Educational Researcher, 18(I), 32-42. https://apps.dtic.mil/sti/pdfs/ADA204690.pdf

Hansman, C. (2008). Adult learning in CoPs. Situating theory in practice. In C. Kimble, P. Hildreth, \& I. Bourdon (Eds.), CoPs Vol. I: Creating learning environments for educators (pp. 293-310). Information Age Publishing.

Hudson, P. (2016). Forming the mentor-mentee relationship. Mentoring \& Tutoring: Partnership in Learning, 24(I), 30-43.

Kennedy, A. (2005). Models of continuing professional development: A framework for analysis. Journal of In-service Education, $31(2), 235-250$.

Kennedy, A. (2014). Understanding continuing professional development: The need for theory to impact on policy and practice. Professional Development in Education, 40(5), 688-697.

Knowles, M. S. (1980). The modern practice of adult learning: From pedagogy to androgogy. Cambridge Books.

Lave, J., \& Wenger, E. (1991). Situated learning: Legitimate peripheral participation. Cambridge University Press.

Manke, M. (1997). Classroom power relations: Understanding student-teacher interaction. Routledge.

Timperley, H., Wilson, A., Barrar, H., \& Fung, I. (2007). Teacher professional learning and development: Best evidence synthesis iteration. Ministry of Education. https://www.educationcounts.govt.nz/topics/bes

Timperley, H., \& Alton-Lee, A. (2008). Reframing teacher professional learning: An alternative policy approach to strengthening valued outcomes for diverse learners. Review of Research in Education, 32(I), 328-369.

Wassenaar, M. (2017). Participating in CoPs. Scope (Art \& Design), 13, 88-94. https://www.thescopes.org/assets/Uploads/ dd26aflb97/I6.-Wassenaar.pdf

Viskovic, A. (2005). 'Community of practice' as a framework for supporting tertiary teachers' informal workplace learning. Journal of Vocational Education and Training, 57(3), 389-4I0. https://doi.org/I0.1080/13636820500200293

Wenger, E. (1998). CoPs: Learning, meaning and identity. Cambridge University Press

Wenger, E. C., \& Snyder, W. M. (2000). CoPs: The organizational frontier. Harvard Business Review, 78(I), $139-146$.

Wong, M. Y. (2016). Teacher-student power relations as a reflection of multileveled intertwined interactions. British Journal of Sociology of Education, 37(2), 248-267. 